\title{
TURBO MIXING THE RAW MATERIAL BY DYNAMIC ROTATION IN PIPELINES
}

THANGARAJ. $\mathrm{K}^{1}$, ATHUL. $\mathbf{V}^{2}$, BHARATHI. $\mathrm{S}^{3}$, MARNEDHI AKHIL RAJU ${ }^{4} \&$ PRAVEEN. $\mathbf{R}^{5}$

${ }^{1}$ Assistant Professor, Department of Electrical and Electronics Engineering, SMVEC, Puducherry, India

2,3,4,5 Student, Department of Electrical and Electronics Engineering, SMVEC, Puducherry, India

\section{ABSTRACT}

The mixing of raw materials is a very time taking process in any industry that involves mixing of raw materials. There is an additional requirement of a tub to mix and the line is stopped for more than 90 minutes so to make it time efficient. The objective is to build a prototype model by applying the mechanism of dynamic mixing of raw materials is introduced. In the process the raw materials to be mixed from different pipe are passed to a single pipe and the pipe to the destination is rotated using motors where fins are fixed inside 3/4th of the mixing is done in pipes while in motion and final mix is done in a small gallon a micro-controller is installed in the gallon to check the ratio of mixture and the remaining mix is mixed In gallon thus time is reduced and extra number of batches can be run on the saved time therefore production is increased.

KEYWORDS: Helix Shaft, on Load Dynamic Mixing, Controlled Homogeneity \& Time Reduction

Received: Jun 06, 2020; Accepted: Jun 26, 2020; Published: Aug 28, 2020; Paper Id.: IJMPERDJUN2020935

\section{INTRODUCTION}

Many chemical industries that uses liquid and semi liquid Raw Materials (RM) for the processing face large time complexity in present methodology of industrial mixing i.e. Stagnant Mixing Line. The line that involve stagnant mixing system as shown in figure 1.1. will consume $60 \%$ more time than all the other process combined together. The time complexity can be reduced to $30 \%$ of its total time and the saved time can be utilized for production of another batch in the same lime thus improving the production scale up to $15 \%$ annually. Stagnant mixing system motors are operated only when the mixer is filled and the wait time is approximately two hours for each batch cycle.

\section{PROBLEM AND INNOVATION}

\section{A. Problem in Existing Model}

Every time the mixer drives a full load of unsmooth colloidal particle that causes friction and reduce the efficiency of the mixer. These mixing containers are rugged in leftover material and need excess labour to maintain the mixers over each batch cycle. The motors and the containers used are of large capacity and consumes more space in the outlet this leads to large power consumption and maintenance [1]. The net production is low compared to new proposed system.

\section{B. Innovation in Proposed Model Prototype}

The innovation in the proposed model is to overcome the Halt in the entire processing line due to delayed settlement of Raw material in mixers by continuous mixing without stopping the line for mixing and running extra batches by adding dynamic rotation in convey or pipelines and setting a feedback mixer for correcting the mix proportion and achieving high homogeneity of the mix in minimum time scale [2]. 


\section{METHODOLOGY IN PROTOTYPE BUILD}

The overall block diagram shows the proposed prototype of turbo mixing of Raw Material using dynamic rotation in pipelines as shown in Fig 1.2. The prototype model uses two motors to drive the load. A $24 \mathrm{~V}$ DC motor is used to drive the conveyor shaft which is designed in screw model to dynamically mix and move the Raw Materials.

A $12 \mathrm{~V}$ Stepper motor which is interfaced with ATMEGA32A is connected to a mixer gallon for completing the remaining mix of the partially mixed substrate from the conveyor [3].

\section{A. Equations and Design}

To design a single-phase rectifier for limiting $230 \mathrm{~V}$ AC to $24 \mathrm{~V}$ DC supply the design parameters to be considered are output current, time, RMS voltage and peak voltage [4]. To convert $12 \mathrm{~V}$ Dc supply to 5V dc supply for peripherals we use IC 7805(voltage regulator) to regulate the voltage to 5V DC. The design of smoothing capacitors for power circuit is given below. To design capacitors $\mathrm{C} 2$ after regulator, the design considerations are: Given: $\mathrm{I}_{\mathrm{out}}=1.2 \mathrm{~A}$, time $=10 \mathrm{~ms}$, Vm $=5$, Vripple voltage $=1.4 \mathrm{~V}$.

The RMS value of voltage of smoothing capacitor after regulator is

$\mathrm{V}_{\mathrm{rms}}=\mathrm{V}_{\mathrm{m}} \times \sqrt{2}$

$5 \times 1.44=7.07$

$\mathrm{V}_{\text {rms }}=7.07$

Voltage drop on capacitor is given by Q:

$\mathrm{Q}=\mathrm{V}_{\text {rms }}-\mathrm{V}_{\text {ripple }}$

$\mathrm{Q}=7.07-1.4$

$\mathrm{Q}=5.67 \mathrm{~V}$.

The capacitor $\mathrm{C} 2$ is calculated by the formula

$C 2=(I \times t) \div Q$

$C 2=\left(1.2 \times 10 \times 10^{-3}\right) \div 5.67$

$C 2=220 \mu F$

The smoothing capacitor of the capacitor $\mathrm{c} 1$ is designed by assuming the same data expect

To design capacitors $\mathrm{C} 2$ after regulator, the design considerations are:

Given: $\mathrm{I}_{\text {out }}=1.2 \mathrm{~A}$, time $=10 \mathrm{~ms}, \mathrm{Vm}=24 \mathrm{~V}$, Vripple voltage $=1.4 \mathrm{~V}$

The RMS value of voltage of smoothing capacitor after regulator is

$\mathrm{V}_{\mathrm{rms}}=\mathrm{V}_{\mathrm{m}} \times \sqrt{2}$

$24 \times 1.44=34 \mathrm{~V}$

$\mathrm{V}_{\mathrm{rms}}=34 \mathrm{~V}$ 
Voltage drop on capacitor is given by Q:

$\mathrm{Q}=\mathrm{V}_{\text {rms }}-\mathrm{V}_{\text {ripple }}$

$\mathrm{Q}=34-1.4$

$\mathrm{Q}=32.6 \mathrm{~V}$.

The capacitor $\mathrm{C} 1$ is calculated by the formula, $C 1=(I \times t) \div Q$

$C 1=\left(1.2 \times 10 \times 10^{-3}\right) \div 32.67$

$C 1=470 \mu F$

The capacitor $\mathrm{c} 1$ and $\mathrm{c} 2$ are designed for the filter circuit.

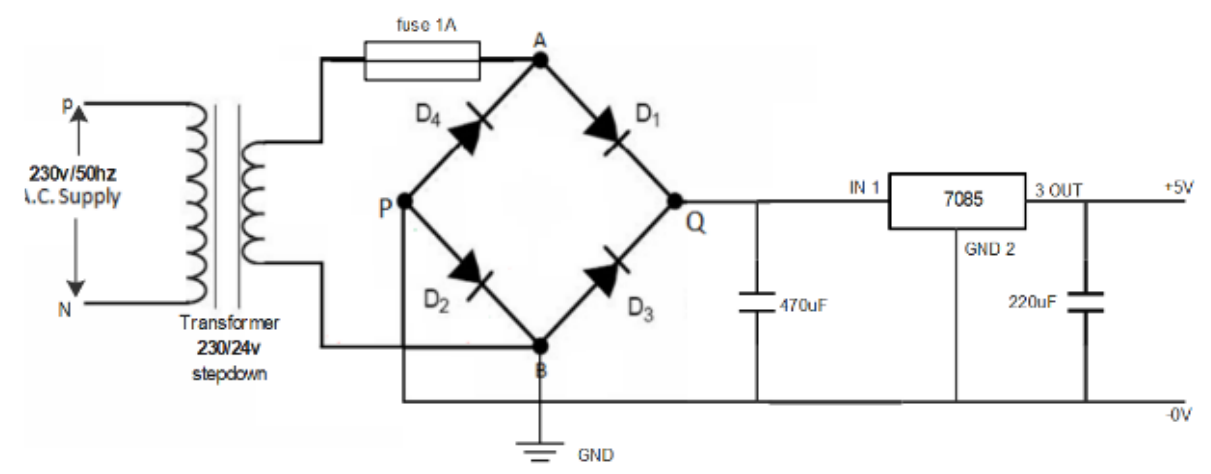

Figure 1: Rectification Circuit for Voltage Regulation.

\section{B. Shaft Dimensions}

- The prototype model consists of a helix screw shaft that drives the mix through the conveyor by dynamically mixing the substrate. The helical screw shaft requires high precision and it is a leading factor in choice of geared DC drive so the dimensions of the shaft are important to design of circuit.

- The helix shaft consists of important parameters to be considered, they are inner core rod diameter, flight clearance, pitch, helix angle and channel depth. Flight clearance is the level of clearance between conveyor wall and shaft blade, this should be maintained as low as possible to produce an effective grinding [5].

- The value of clearance should be maintained below $0.3 \mathrm{~cm}$. Pitch of the shaft is the interval between one blade and other blade center helix angle should be around 20deg to 30deg for correct pitch of the shat. Pitch vary for each shaft by difference in diameter. Channel depth is the level of clearance from the root core rod to the inner wall of conveyor this gap is utilized for particle flow and grinding [6].

- Helix angle $=20 \mathrm{deg}$, Pitch $=4.0 \mathrm{~cm}$, Flight clearance $=0.1 \mathrm{~cm}$, channel depth $=4.0 \mathrm{~cm}$, root rod length $=25 \mathrm{~cm}$, Rod radius $=1.0 \mathrm{~cm}$, Total diameter $=8 \mathrm{~cm}$.

- The weight of the screw shaft prototype is important of the translational force which is vital factor for choosing the 
gear motor for drive and the weight is reduced to 300 grams by printing the shaft in $3 \mathrm{D}$ printer as one single alloy. The figure 2 we can visualize the dimensions of the shaft.

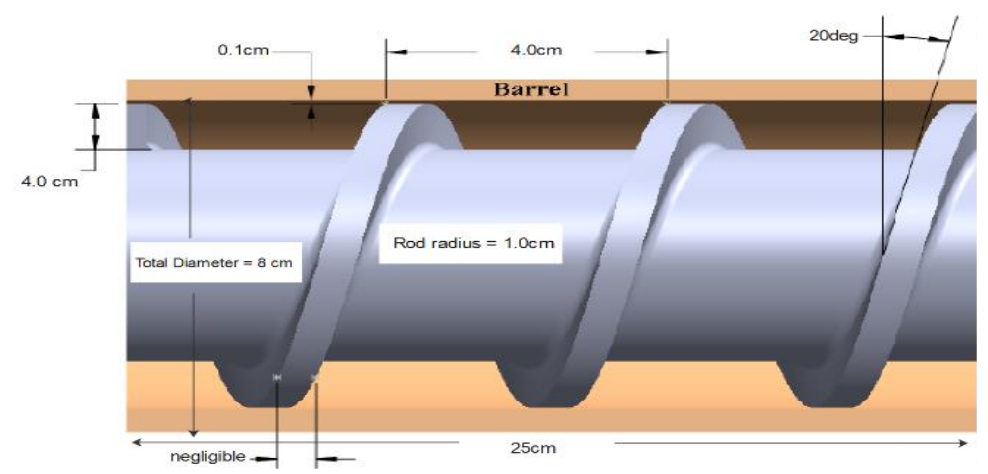

Figure 2: Shaft Dimensions.

\section{MOTOR DESIGN}

The important parameters in selection of a geared motors are rated torque should be greater than the stall torque, the gear ratio should be chosen according to the maximum torque, the rated current and rated voltage should be maintained by regulation circuits [7]. The design parameters are voltage, current, rated torque, stall torque, speed, efficiency and output power [8]. Given parameters: voltage $=24 \mathrm{~V}$, no load current $=120 \mathrm{~mA}$, Rated current $=420 \mathrm{~mA}$, rated speed $=485 \mathrm{RPM}$ to $600 \mathrm{RPM}$, Rated torque $=19.6 \mathrm{Nm}$. Gear ratio selection, for given parameters the gear ratio is from the gear ratio table of the geared motor manual below.

Table 1: Gear Ratio of 24V DC Geared Motor

\begin{tabular}{|c|c|c|c|c|c|c|c|c|c|c|c|c|c|}
\hline \multicolumn{14}{|c|}{ Allowable torque-speed characteristics } \\
\hline \multirow{2}{*}{ MODEL } & \multirow{2}{*}{\multicolumn{2}{|c|}{ GEAR RATIO }} & \multirow{2}{*}{\multicolumn{2}{|c|}{$\frac{1}{12.1}$}} & 1 & 1 & 1 & 1 & 1 & 1 & 1 & 1 & 1 \\
\hline & & & & & $\overline{17.6}$ & $\overline{20.6}$ & $\overline{25.5}$ & $\overline{42.1}$ & $\overline{61.2}$ & $\overline{71.7}$ & $\overline{88.7}$ & 104 & 129 \\
\hline \multirow{3}{*}{$\begin{array}{c}\text { TG-01F-EU } \\
\text { (24V) }\end{array}$} & \multicolumn{2}{|c|}{ SPEED (r/min) } & \multicolumn{2}{|c|}{316} & 225 & 194 & 149 & 94.1 & 62.6 & 53 & 43 & 36.7 & 29.5 \\
\hline & \multicolumn{2}{|c|}{ TORQUE $(\mathrm{mN} \cdot \mathrm{m})$} & \multicolumn{2}{|c|}{8.82} & 9.8 & 9.8 & 19.6 & 19.6 & 19.6 & 49 & 58.8 & 68.6 & 88.2 \\
\hline & \multicolumn{2}{|c|}{ TORQUE $(\mathrm{kgf} \cdot \mathrm{cm})$} & \multicolumn{2}{|c|}{0.09} & 0.1 & 0.1 & 0.2 & 0.2 & 0.4 & 0.5 & 0.6 & 0.7 & 0.9 \\
\hline \multirow{3}{*}{$\begin{array}{c}\text { TG-01G-EU } \\
(24 \mathrm{~V})\end{array}$} & \multicolumn{2}{|c|}{ SPEED (r/min) } & \multicolumn{2}{|c|}{609} & 425 & 365 & 289 & 177 & 121 & 103 & 83 & 70.9 & 57.1 \\
\hline & \multicolumn{2}{|c|}{ TORQUE $(\mathrm{mN} \cdot \mathrm{m})$} & \multicolumn{2}{|c|}{8.82} & 8.82 & 9.8 & 19.6 & 19.6 & 39.2 & 49 & 58.8 & 68.6 & 88.2 \\
\hline & \multicolumn{2}{|c|}{ TORQUE $(\mathrm{kgf} \cdot \mathrm{cm})$} & \multicolumn{2}{|c|}{0.09} & 0.1 & 0.1 & 0.2 & 0.2 & 0.4 & 0.5 & 0.6 & 0.7 & 0.9 \\
\hline \multirow{3}{*}{$\begin{array}{c}\text { TG-O1H-EU } \\
(12 \mathrm{~V})\end{array}$} & \multicolumn{2}{|c|}{ SPEED (r/min) } & \multicolumn{2}{|c|}{600} & 420 & 361 & 285 & 175 & 119 & 101 & 81.8 & 69.9 & 56.3 \\
\hline & \multicolumn{2}{|c|}{ TORQUE $(\mathrm{mN} \cdot \mathrm{m})$} & \multicolumn{2}{|c|}{8.82} & 9.8 & 9.8 & 19.6 & 19.6 & 39.2 & 49 & 58.8 & 68.6 & 88.2 \\
\hline & \multicolumn{2}{|c|}{ TORQUE $(\mathrm{kg} f \cdot \mathrm{cm})$} & \multicolumn{2}{|c|}{0.09} & 0.1 & 0.1 & 0.2 & 0.2 & 0.4 & 0.5 & 0.6 & 0.7 & 0.9 \\
\hline \multirow{2}{*}{ GEAR RATIO } & \multirow{2}{*}{$\underset{(\mathrm{mm})}{\mathrm{L}}$} & \multirow{2}{*}{\multicolumn{2}{|c|}{ STAGE }} & \multicolumn{4}{|c|}{ TORQUE } & \multirow{2}{*}{\multicolumn{2}{|c|}{$\begin{array}{l}\text { WEIGHT } \\
\text { (g) }\end{array}$}} & & & & \\
\hline & & & & & $\mathrm{nN} \cdot \mathrm{m})$ & \multicolumn{2}{|c|}{$(\mathrm{kgf} \cdot \mathrm{cm})$} & & & & & & \\
\hline $1 / 12.1 \sim 1 / 25.5$ & 21 & \multicolumn{2}{|l|}{2} & & 98 & & 1 & \multicolumn{2}{|c|}{34} & & & & \\
\hline $1 / 42.1 \sim 1 / 129$ & 26 & 3 & & & 147 & & .5 & 36 & & & & & \\
\hline
\end{tabular}

From the above table the gear ratio for the above parameters can be given by $1 / 61.2$ for selected motor according to rated torque and rated speed [9]. Type TG55LA Geared motor is chosen and the rated speed without gear is 3700 RPM weight of the motor is around 350 grams. These are the parameters required for designing the load characteristics of dc motor [10].

\section{A. Load Calculation for Motor Selection}

From the design parameter obtained from datasheet the given values are voltage $=24 \mathrm{~V}$, no load current $=120 \mathrm{~mA}$, Rated 
current $=420 \mathrm{~mA}$, rated speed $=485 \mathrm{RPM}$ to $600 \mathrm{RPM}$, Rated torque $=19.6 \mathrm{Nm}$. Radius $=0.1 \mathrm{~cm} ;$ Force $=0.3 \mathrm{~kg}$. The load torque due to the shaft is given by the formula

Torque $=(9.81 \times$ force $\times$ radius of core $) \times 1 \div$ gear ratio

$T=(9.81 \times 0.1 \times 0.3) \times\left(1 \div \frac{1}{61.2}\right)$

$\mathrm{T}=18.01 \mathrm{Nm}$

The output power of the motor is given by the formula

$$
\begin{aligned}
& P=\frac{2 \times \pi \times N \times T}{60} \\
& P=\frac{2 \times \pi \times 600 \times 18.01}{60} \\
& P=1131.60 \mathrm{~W}
\end{aligned}
$$

The speed of DC motor is calculated by the formula

$$
\begin{aligned}
& \text { Speed }=\frac{\text { Power }}{\text { Torque }} \\
& \text { Speed }=\frac{1131.60 \mathrm{~W}}{18.01 \mathrm{Nm}} \\
& \text { Speed }=62.83 \mathrm{RPM}
\end{aligned}
$$

The input power of DC geared motor is given by

$P i=I \times V$

$P i=4.2 A \times 24 V$

$\mathrm{Pi}=100.8 \mathrm{~W}$

The efficiency of the motor is given by

$$
\begin{aligned}
& E=\frac{\text { output power }}{\text { input power }} \% \\
& E=\frac{1131.60}{100.1} \% \\
& \mathrm{E}=11.304 \%
\end{aligned}
$$

Thus, the load characteristics of DC motor are calculated and appropriated motor can be purchased from this design.

- From the design the load requirements have been calculated and the motors are chosen as per the data obtained [12]. Listed below are the motors required for prototype model and their specifications are tabulated below.

- DC geared motor.

- DC Stepper motor 
Table 2: Motor Specification

\begin{tabular}{|c|l|l|l|}
\hline Sl & \multicolumn{1}{|c|}{ Description } & \multicolumn{1}{c|}{ Motor 1 } & \multicolumn{1}{|c|}{ Motor 2 } \\
\hline 1. & Type & DC geared. & Stepper motor \\
\hline 2. & Rated voltage & $24 \mathrm{~V}$ & $24 \mathrm{~V}$ \\
\hline 3. & Rated current & $4.2 \mathrm{~A}$ & $1.33 \mathrm{~A}$ \\
\hline 4. & Rated torque & $19.6 \mathrm{Nm}$ & $0.31 \mathrm{Nm}$ \\
\hline 5. & Rated speed & $60 \mathrm{RPM}$ & $4000 \mathrm{RPM}$ \\
\hline 6. & Gear ratio/Step angle & $1 / 61.2$ & $1.8 \mathrm{deg}$ \\
\hline 7. & Weight & 350 grams & $1 \mathrm{~kg}$ \\
\hline 8. & Efficiency/Steps per revolution & $11.30 \%$ & \multicolumn{1}{|c|}{200} \\
\hline
\end{tabular}

\section{B. Design of Operational Amplifier}

- The PH sensors produce an output of negligible voltage fewer than $100 \mathrm{mV}$ which is varied in different temperature so an non inverting amplifier is required to amplify the negligible voltage and feedback the error voltage caused by temperature change [13].

- To design an non inverting amplifier, let us assume the ideal room temperature as $25 \mathrm{deg}$ Celsius. The PH measured output of electrode is typically $59.16 \mathrm{mV}$ per $\mathrm{PH}$ at $25^{\circ} \mathrm{C}$ for an output range of $-414 \mathrm{mV}$ to $414 \mathrm{mV}$ ranging 1 to $14 \mathrm{PH}$ at $25^{\circ} \mathrm{C}$.

- The output impedance of PH electrode is extremely high, ranging from $10 \mathrm{M} \Omega$ to $1000 \mathrm{M} \Omega$ the error of $30 \mathrm{nV}$ is observed and this error can be corrected using the LMP7721 op amp. The maximum output swing is limited to +/$2.4 \mathrm{~V}$.

Table 3: Ph Amplifier Specifications

\begin{tabular}{|c|c|c|c|c|c|c|c|}
\hline SI & Description & Offset Voltage & Temperatue & Vin & Gain & Ph Range & Ph Range in v \\
\hline 1. & LMP7721 & $512 \mathrm{mV}$ & $25^{\circ} \mathrm{C}$ & $4.2 \mathrm{~V}$ & 4.6 & $0-14$ & $-414 \mathrm{mv} / 414 \mathrm{mV}$ \\
\hline
\end{tabular}

The gain of the amplifier with given input voltage $2.4 \mathrm{~V}$ to offset voltage $0.512 \mathrm{~V}$ is given by

Gain $=\frac{2.4}{0.512}$

$\mathrm{A}=4.6$

So, at $25^{\circ} \mathrm{C}$ the ideal gain of a PH amplifier with offset voltage of $512 \mathrm{mV}$ is 4.6.

\section{METHODOLOGY AND CIRCUIT DIAGRAMS}

\section{A. Overall Description}

The overall circuit diagram consists of a rectified AC to DC circuit for low voltage peripherals. The atmega32 is used to control the mixer in a secondary gallon, the raw materials from the line is travelling through a cylindrical conveyor and to mix the substrate dynamically an helical shaft in model of screw is attached with a DC geared motor to drive and simultaneously mix the substrate once the mix reaches end of this drive a gallon with a mixer setup is employed to correct the homogeneity of the mix the substrate is checked by employing a PH sensor the block diagram of the model [14]. 


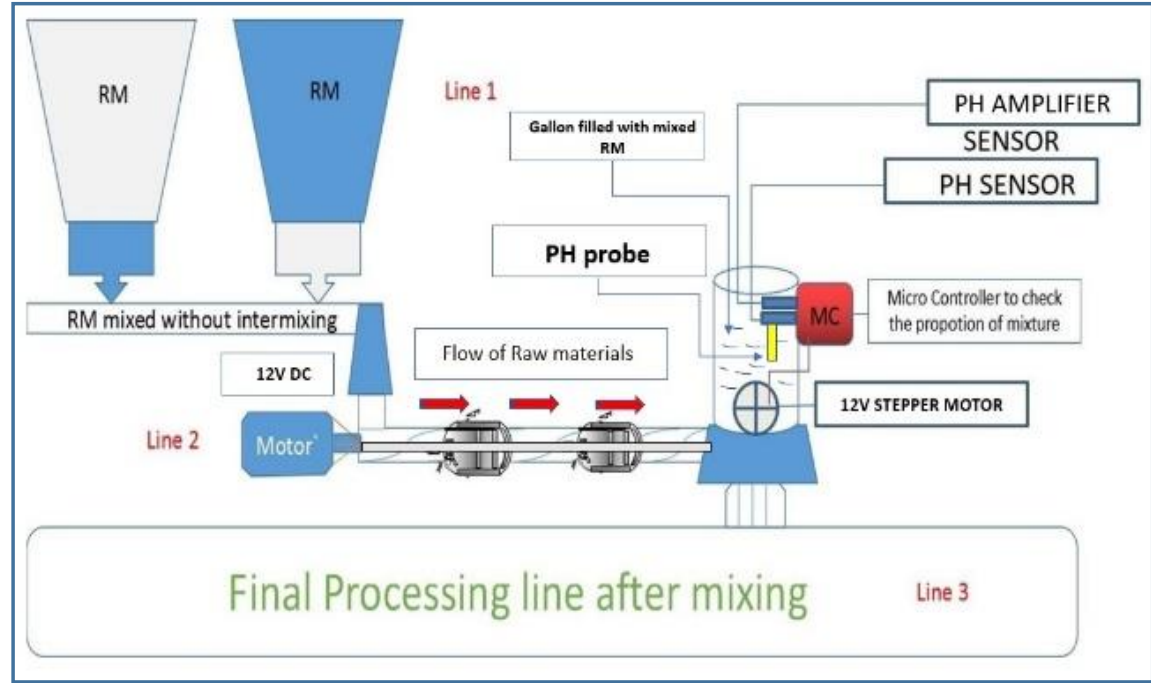

Figure 3: Block Diagram.

\section{B. Circuit Diagram}

- The circuit diagram consists of three major blocks a simple DC geared motor is given a supply of $24 \mathrm{~V}$ from an rectified supply that converts $230 \mathrm{~V}$ AC to $24 \mathrm{~V}$ DC using a stepdown transformer [15].

- The second layer is circuit is helical shaft which is driven by geared motor.

- The third part in circuit diagram is the control part that checks the homogenity of the mix by a mixer with a stepper motor and the PH sensor and mixes till there is no error in homogienety in the mix vs the reference material.

- PH sensor works on the principle of calculating the bumber of hydrogen ions with the given reference value of the mix. The PH sensor uses an electrode to measure the voltage for appropirate PH.

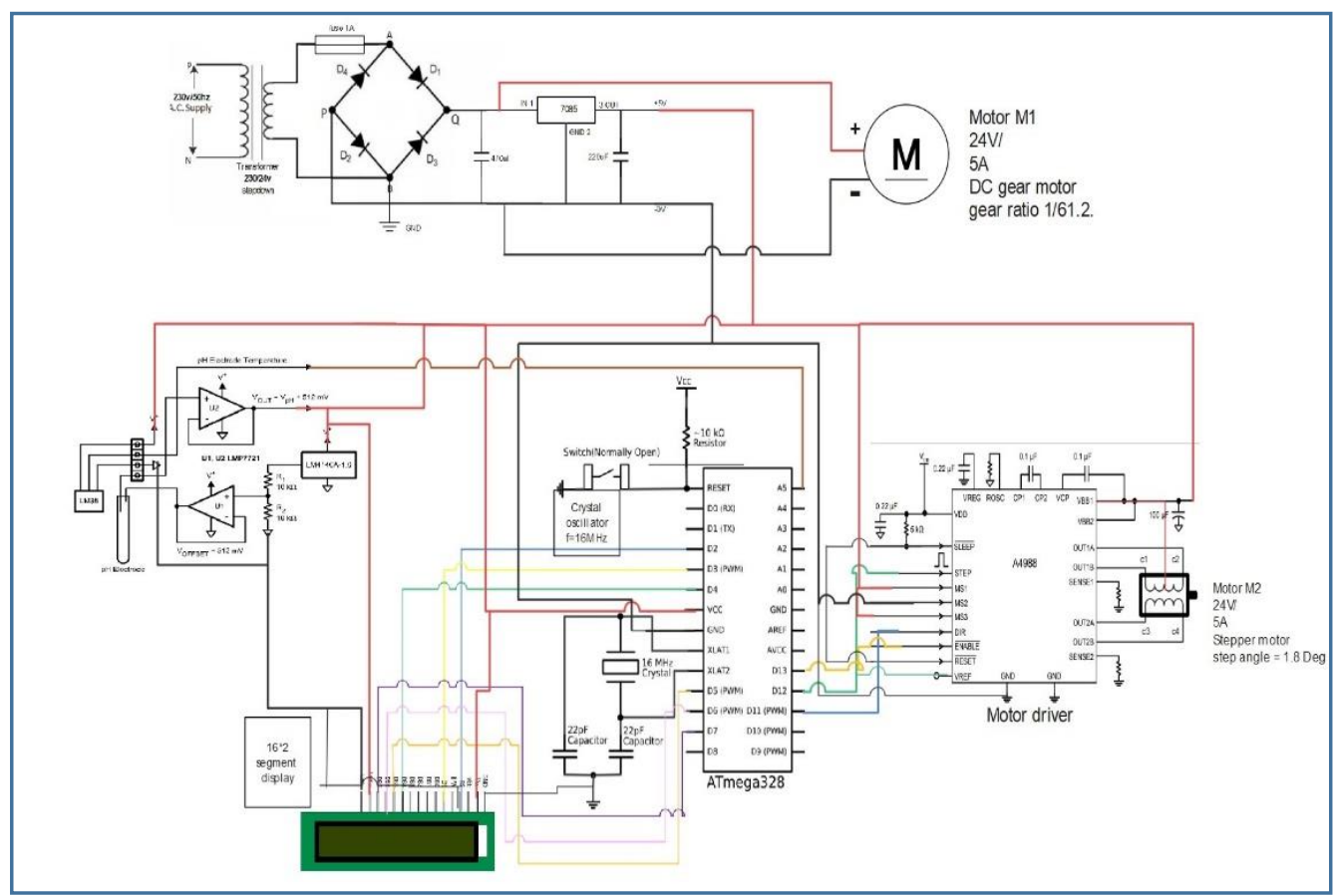

Figure 4: Overall Circuit Diagram. 


\section{SIMULATION AND INFERENCE}

The simulation for the shaft is done in EDEM and definite element analysis is observed for change in difference in torque with time and control circuit simulation is done in Proteus design suite.

\section{A. EDEM Analysis}

In CAD model of the conveyor is designed with precision dimensions as shown in the figure 5 below and analyzed for change in torque and compressive force with time.

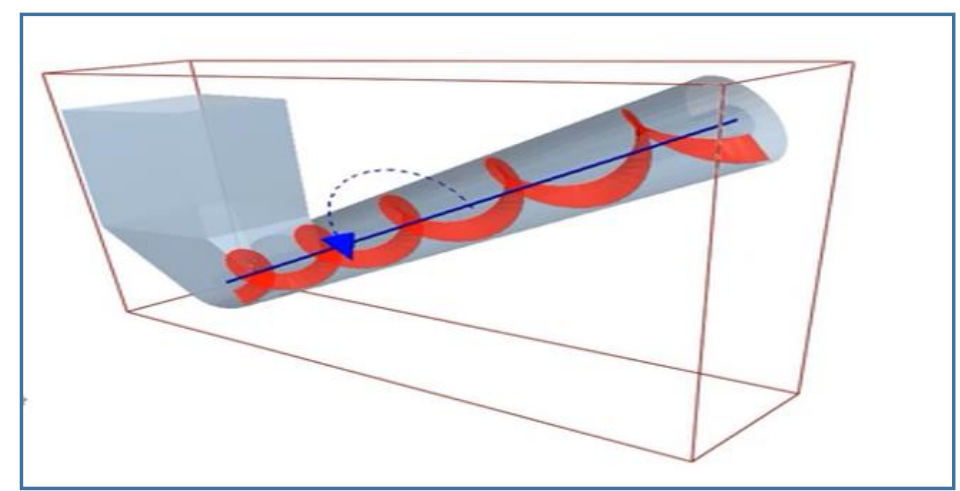

Figure 5: Screw Conveyor.

\section{A. Torque vs Time Characteristics}

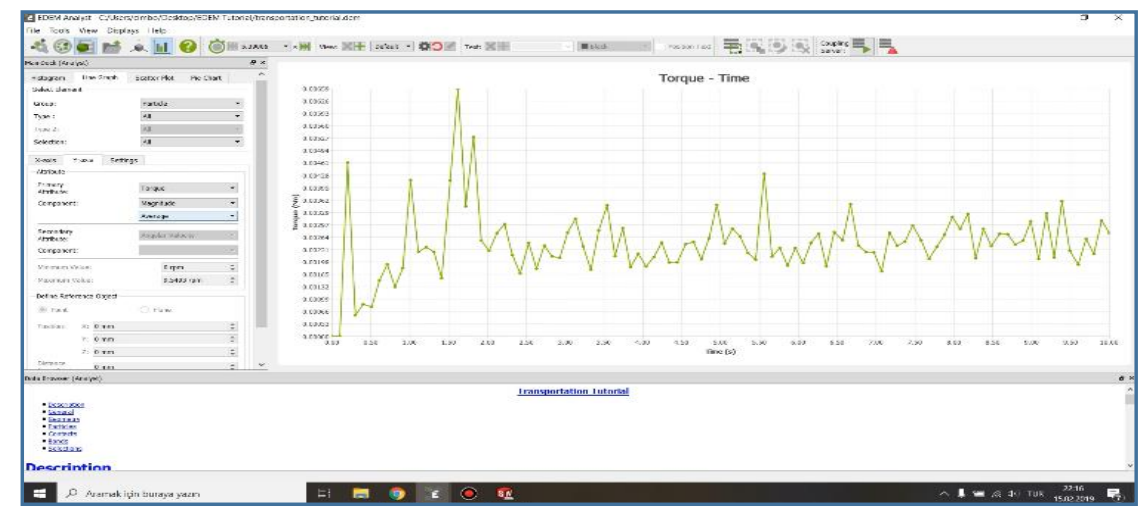

Figure 6: Torque vs Time Graph.

The change in torque vs time is analyzed through EDEM simulation software and the graph is analyzed. The graph shows minimum of $0.6 \mathrm{NM}$ rise of torque at full load before grind. The maximum torque is $18.6 \mathrm{Nm}$ and rated torque is $19.6 \mathrm{Nm}$ so the $0.6 \mathrm{Nm}$ torque will not affect the motor at full load once the shaft grinds the particles the torques is reduced again this can be observed in the graph clearly in figure 6 below.

\section{B. Comphressive Force vs Time Graph}

Same as the above graph the compressive force experienced by the shaft while the load is driven in the conveyor the analyzed, the compressive force peaks at when the new particle enter and about to be grinded, the force is minimum before and after the grinding. 


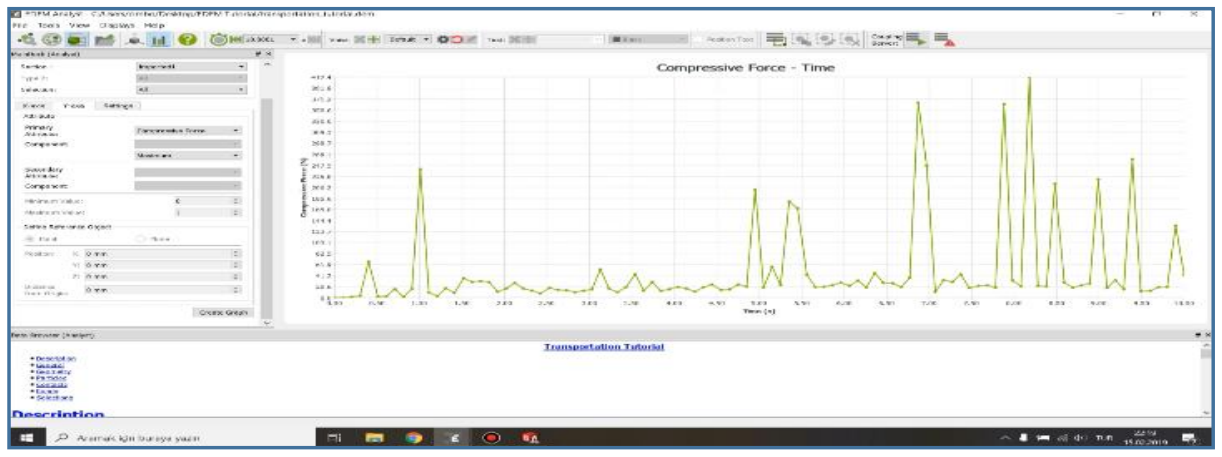

Figure 7: Compressive Force vs Time Graph.

\section{Inference}

From the torque vs time graph, the torque at different time can be calculated and at what instance the maximum torques occurs can be inferred from table 3 below

Table 3: Torque vs Time in Definite Element Analysis

\begin{tabular}{|c|c|c|}
\hline SL & Time (m) & Torque Nm \\
\hline 1. & 0.1 & 0.3 \\
\hline 2. & 0.2 & 0.5 \\
\hline 3. & 0.4 & 0.12 \\
\hline 4. & 0.6 & 0.42 \\
\hline 5. & 0.8 & 0.19 \\
\hline 6. & 1.0 & 0.26 \\
\hline
\end{tabular}

From the above table it is observed that the torques initially from $0 \mathrm{sec}$ to $2 \mathrm{sec}$ is maximum up to $0.6 \mathrm{Nm}$ is increased from $18.6 \mathrm{Nm}$ so only when the particle are not mixed torques are high after the mixing takes place the torque reduces to $0.2 \mathrm{Nm}$. The minimum torque rate is $0.2 \mathrm{Nm}$ observed.

The force is high then the particle reaches the end of the Conveyor because it fills the conveyor and the shaft has To operate at full load.

Table 4:Compressive Force vs Time

\begin{tabular}{|c|c|c|}
\hline SL & Time (M) & Force(N) \\
\hline 1. & 0.1 & 247.5 \\
\hline 2. & 0.2 & 20.6 \\
\hline 3. & 0.4 & 25 \\
\hline 4. & 0.6 & 22 \\
\hline 5. & 0.8 & 350.6 \\
\hline 6. & 1.0 & 123 \\
\hline
\end{tabular}

\section{Proteus Design Circuit}

In this design circuit the proteus model of microcontroller is Designed and simulated to check the integrity of control circuit by virtually feeding the hex code into Simulink model. 


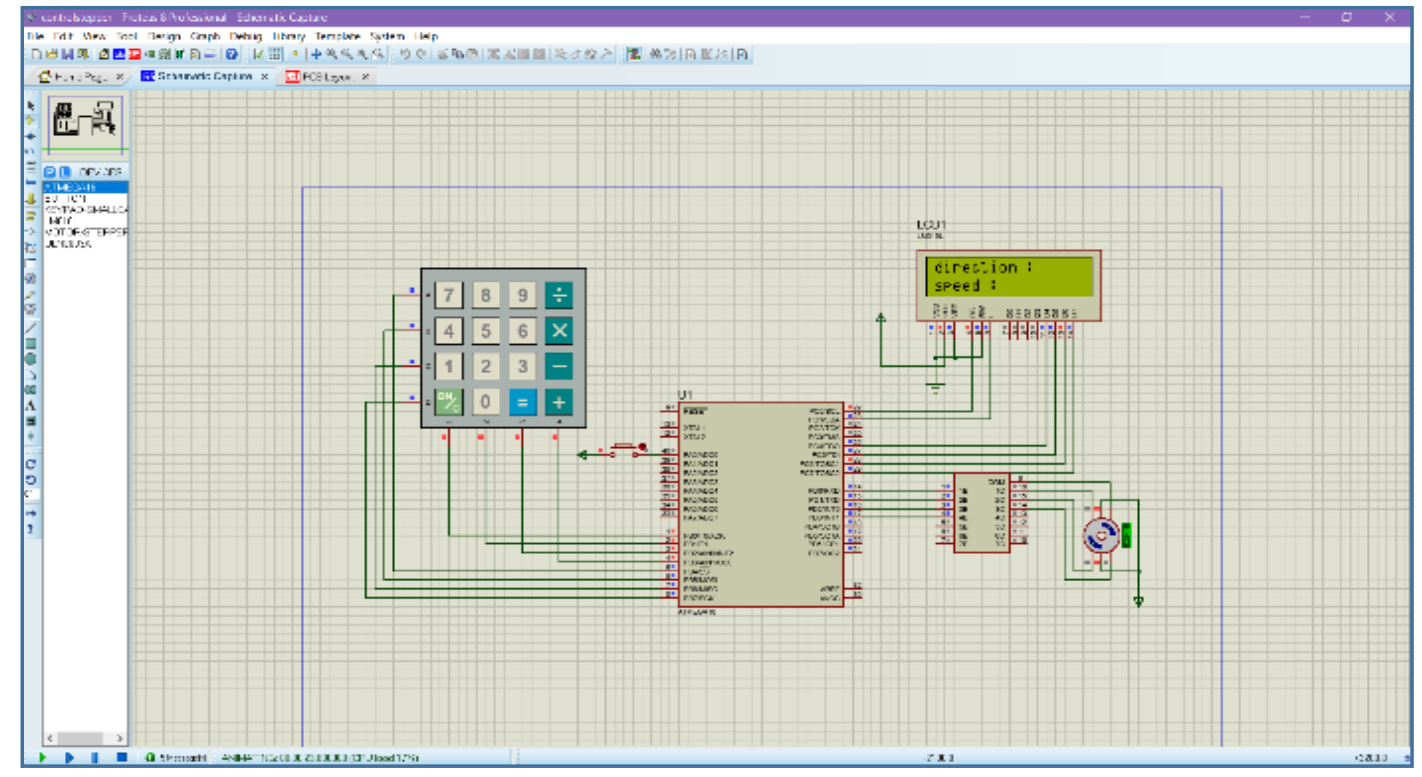

Figure 8: Proteus Design Circuit.

A keypad and $16 * 2$ segment display are used to display the torque and speed control of the circuit to ensure the control integrity of the code.

\section{CONCLUSIONS}

In this paper a prototype model of a dynamic mixer for industrial mixing is designed and tested for implementation the respective analysis if data regarding the performance is tabulated and graphically presented in the paper. The time consumption is reduced and the production can be more efficient using this technique than the conventional one.

\section{REFERENCES}

1. "Quality by Design for Continuous Powder Mixing” by Patricia Maribel Portillo, A Dissertation submitted to the Graduate School-New Brunswick Rutgers, The State University of New Jersey.

2. Berthiaux H., Marikh K, Mizonov V., Ponomarev D., Barantzeva E., 2004, "Modeling Continuous Powder Mixing by Means of the Theory of Markov Chains", Particulate Science and Technology, 22, 4, 379-389.

3. Alexander A., Muzzio F.J., 2001, “Batch size increase in dry blending and mixing”. (New York: Marcel Dekker).

4. Alexander A., Shinbrot T., Muzzio F.J., 2003, “Segregation Patterns in V-Blenders, Chemical Engineering Science”, 58, 487496.

5. Alexander A.W., Chaudhuri B., Faqih A.M., Muzzio F.J., Davies C., Tomassone M.S., 2006, Avalanching flow of cohesive powders, Powder Technology, 164, 1, 13-21.

6. XU, Changchun, and Haeng Muk Cho. "Effect of Dual Fuel Mixing Performance in Rcci Engine Cylinder." International Journal of Mechanical and Production Engineering Research and Development (IJMPERD) 10. 1, Feb 2020, 73-82

7. Toson P., Lopes D.G., Paus R., Kumar A., Geens J., Stibale S., Quodbach J., Kleinebudde P., Hsiao W.-K., Khinast J.,Modelbased approach to the design of pharmaceutical roller-compaction processes (International Journal of Pharmaceutics: X, Volume 1, 2019)

8. T. Bay, C. W. Ross, J. C. Andrews, J. L. Gilhand, "Dynamic control of the cement process with a digital computer system", IEEE Transactions on Ind. \& Gen. Appl., vol. 4, pp. 294-298, 1968. 
9. Umesh, K. S., and V. P. K. Rajagopal. "Cfd Analysis Of Exhaust Manifold Of Multi-Cylinder Si Engine Todetermine Optimal Geometry For Reducing Emissions." International Journal of Automobile Engineering Research and Development (2013): 4556.

10. “Continuous Twin Screw Wet Granulation and Drying —Control Strategy for Drug Product Manufacturing”, Dahlgren, G., Tajarobi, P., Simone,Stanton, C., Bajwa, G. Journal of Pharmaceutical Sciences (2019).

11. M.H. Rashid, "Power Electronics Handbook", Academic Press, New York, 2001.

12. Alexander A., Shinbrot T., Muzzio F.J., 2001, Granular Segregation in the Double-Cone Blender: Transitions and Mechanisms, Phys. Fluids, 13, 3, 578-587.

13. Naik, R. T., and C. Nilesh. "Emission characteristic of a high speed diesel engine." International Journal of Mechanical Engineering, 5, 2936 (2016).

14. Arratia P.E., Duong N.-H, Muzzio F.J., Godbole P., Lange A., Reynolds S., 2006, Characterizing mixing and lubrication in the Bohle Bin blender, Powder Technology, 161, 202 - 208.

15. Riddle, P. (2013). pH meter and their electrodes :calibration, maintenance and use, 202-205. Wilde, F. D., \& Gibs, J. (n.d.). Turbidity. In U.S. Geological Survey TWRI Book. CRC Press Taylor\& Franics Group.

16. Pittala, Suresh, and T. Diriba. "Computational Fluid Dynamics Analysis of Impeller Design For A Pump." International Journal of Mechanical Engineering (IJME) 5.4.

17. S. Waje, B. Thorat, A. Mujumdar, Screw conveyor dryer: process and equipment design, Dry. Technol. 25 (1) (2007) $241-247$.

18. P. Owen, P. Cleary, Prediction of screw conveyor performance using the Discrete Element Method (DEM), Powder Technol. 193 (3) (2009) 274-288. 
